\title{
A study of constitutive heterochromatin and NOR banding in three species of Indian major carps from the State of Haryana, India
}

\begin{abstract}
Neeru
Department of Zoology, Kurukshetra University, Kurukshetra-136119 (Haryana), India

Anita Bhatnagar*

Department of Zoology, Kurukshetra University, Kurukshetra-136119 (Haryana), India Abhay Singh Yadav

Department of Zoology, Kurukshetra University, Kurukshetra-136119 (Haryana), India

*Corresponding author. E-mail: anitabhatnagar@gmail.com

Abstract

Cytogenetic survey of fishes becomes increasingly important to establish chromosomal relation between the teleosts, to have a glimpse of the relation between chromosomal evolution and differentiation of vertebrate species. In the present study, Chromosome banding studies was done in three species of carps i.e. Catla catla (Hamilton, 1822), Labeo rohita (Hamilton, 1822) and Cirrhinus mrigala (Hamilton, 1822). Diploid chromosome number 50 was observed in all 3 species of carps. The chromosomes of $C$. catla, L. rohita and C. mrigala showed constitutive heterochromatin at telomeric and centromeric regions of chromosomes. The Ag-NOR (Argyrophilic-Nucleolus Organizer Region) bands were observed on homologous chromosome pair number 11 in C. catla, $15^{\text {th }}$ chromosome pair in L. rohita. In C. mrigala, the Ag- NOR staining elucidated the presence of darkly stained NORs on the terminal region of the long arms of one of the chromosome. Another homologue of this chromosome pair could not be localized due to scattering of chromosomes. The results depict that variation in ecological conditions with time due to human activities can not only affect the chromosomal number but also chromosomal morphology.
\end{abstract}

Keywords: Catla catla, Labeo rohita, Cirrhinus mrigala, Chromosomes, Heterochromatin

\section{INTRODUCTION}

Cyprinidae is a large family of freshwater fishes which is commonly called the carp family. The vast majority of bony fishes belong to this family and these are widely distributed in freshwater resources (Abdoli, 1999). The Indian subcontinent supports 2500 fish species and constitutes $8.93 \%$ of the World's fish diversity (Johal and Jha, 2010). In fishes, cytogenetic data is important because in this group the usual morphotaxonomical characters are not so clear and they have undergone a number of adaptational changes during the process of evolution. The increasing knowledge of chromosomes can provide reliable information on the phylogenetic relationship in the Cyprinidae to a certain extent (Kalbassi et al., 2008).

Systematically, C. catla, L. rohita and C. mrigala belongs to class Teleostei, order Cypriniformes, family Cyprinidae (Jayaram, 1999). The study of fish chromosomes was initiated in India from 1960 s by using basically the methodologies available for mammals. Karyological studies provide basic information on the number, size and morphology of chromosomes (Tan et al., 2004) that is important to undertake chromosome manipulation

\section{Article Info}

DOI:10.31018/jans.v10i2.1731

Received: November 24, 2017

Revised: March 6, 2018

Accepted: March 15, 2018

\section{How to Cite}

Neeru, et al. (2018). A Study of constitutive heterochromatin and NOR banding in three species of Indian major carps from the State of Haryana, India. Journal of Applied and Natural Science, 10 (2): $535-539$ in fishes (Khan et al., 2004). However, the studies dealing with karyotype of fishes are few because of large number and small size of chromosomes. Chromosome banding studies may help in identifying species and the homologous pairs of chromosomes in a karyotype. Banding patterns are used not only to identify chromosomes in a normal karyotype, but also in aneuploid situations (O'Connor, 2008). They permit the identification of small parts of chromosomes involved in translocations, deletions and other rearrangements. The ability to identify chromosomes and parts of chromosomes has made accurate gene mapping feasible. C-banding is thought to demonstrate constitutive heterochromatin, mainly at the centromeres. The chromosomes are typically exposed to denaturation with a saturated solution of Barium hydroxide, prior to Giemsa staining. C-bands were the result of differential denaturation and annealing of the DNA in them.

Chromosome banding study may also help in identifying the parentage of hybrids that are sometimes found in nature. Absence of proper and repeatable methodologies also appears to be one of the constraints in the progress of fish chromosome banding studies. Banding of NORs makes 
relatively easy to distinguish species with similar karyotypes. NOR staining is useful for studies of chromosomes with double satellites, chromosome polymorphism and structural abnormalities involving satellite regions. Variations in NOR number and size could also be due to differential transcriptional activity necessary under changing ecophysiological conditions or else due to other factors like age, disease etc. (Lakra et al., 2007; Neeru, 2014; Unal et al., 2014). Therefore the present studies were conducted to study the chromosome banding in three species of carps, Catla catla (Hamilton, 1822), Labeo rohita (Hamilton, 1822) and Cirrhinus mrigala (Hamilton, 1822).

\section{MATERIALS AND METHODS}

The fishes (C. catla, L. rohita, C. mrigala ) were obtained from local fish culture farm and transported to the Fish and Fisheries laboratory of Department of Zoology, Kurukshetra University, Kurukshetra. Kidney and gill epithelium tissue were used for chromosomal banding analysis. The preparation of chromosomes was performed according to air drying technique given by Tjio and Whang (1965). Each specimen was injected intraperitoneally with a colchicine solution $(0.05 \% ; 1$ $\mathrm{ml} / 100 \mathrm{gm}$. body weight). The fishes were maintained in a well aerated aquarium and after $2 \mathrm{hr}$., Kidney tissue was extracted and placed in hypotonic solution of $0.56 \% \mathrm{KCl}$. After 30 minutes in the hypotonic solution, the cellular suspension was centrifuged at $1000 \mathrm{rpm}$ for 10 minutes. The hypotonic solution was discarded and the pellet was suspended and washed 3 times in methanol: glacial acetic acid (3: 1) (Tjio and Whang, 1965). After centrifugation at $1000 \mathrm{rpm}$ for 10 minutes, the drops of cellular suspension was put on a clean grease free microscopic slide, previously chilled in a freezer from a height of 2 feet. The slides were allowed to air dry.

C-banding was done by using the method given by Sumner (1972) with slight modification and it was observed that the slides which were 7 days old depicted the best results for $\mathrm{C}-$ bands. The slides were treated with $5 \%$ freshly prepared saturated solution of $\mathrm{Ba}(\mathrm{OH})_{2}$ at $52^{\circ} \mathrm{C}$ for $1-2$ minutes in water bath. Then slides were rinsed thoroughly in two successive changes of double distilled water at $52^{\circ} \mathrm{C}$ for 2 minutes to remove traces of $\mathrm{Ba}(\mathrm{OH})_{2}$. The slides were put in $0.6 \% \mathrm{HCl}$ solution at room temperature for 15 minutes and again rinsed in distilled water for 2 minutes. Slides were air dried and incubated for 1 hour in 2X SSC (1.75gm Sodium Chloride and $0.88 \mathrm{gm}$ Sodium Citrate in $100 \mathrm{ml}$ Distilled water) in water bath at $65^{\circ} \mathrm{C}$ and then rinsed in water at $65^{\circ} \mathrm{C}$. The slides were air dried and then stained for 45 minutes in $4 \%$ Giemsa solution (760 mg Giemsa powder, $50 \mathrm{ml}$ Methanol and $50 \mathrm{ml}$ Glycerol) at $\mathrm{pH}=6.8$.
For Silver staining of chromosomes, the method given by Howell and Black (1980) was followed. The slides were dried properly at $40{ }^{\circ} \mathrm{C}$ for $4-5 \mathrm{hr}$. Then 4 drops of developing solution was mixed with 8 drops of $50 \% \mathrm{AgNO}_{3}$ solution and placed on the unstained slide with the help of pasture pipette and covered with cover glass. The slides were then incubated at $50{ }^{\circ} \mathrm{C}$ for 3-5 min. till solution becomes golden brown colour. The slides were rinsed with distilled water. The slide was then air dried and observed under microscope. Mitotic metaphase were photographed by using Olympus C-7070 wide zoom camera at magnification of $1000 \mathrm{X}$ and used for preparation of karyotypes and banding patterns.

\section{RESULTS}

Catla catla (Hamilton, 1822) [2n = 50]: The somatic metaphase showed the presence of 50 chromosomes, confirming this to be diploid number of C. catla (Fig. 1A). The chromosomes of $C$. catla showed constitutive heterochromatin at telomeric and centromeric regions of chromosomes (Fig.1B). However, some chromosomes showed prominent dark bands while others showed very faint bands. The Ag-NOR banding revealed a pair of NORs situated terminally on short arm of homologous chromosome pair number 11 (submetacentric) (Figs.1C, 1D). Short arms of both the homologue were uniformly stained without any heteromorphy.

Labeo rohita (Hamilton, 1822) $[2 \mathrm{n}=50]$ : The somatic metaphase showed the presence of 50 chromosomes in case of $L$. rohita (Fig.2A). $L$. rohita showed constitutive heterochromatin at telomeric and centromeric regions of chromosomes. However, some chromosomes showed prominent dark bands, others showed very faint bands. The NORs on the chromosomes of this fish were found localized on the $15^{\text {th }}$ chromosome pair which is subtelocentric (Figs. 2C, 2D). The NOR was observed on telomeric region of short arm on one of homologue and telomeric region of long arm on another homologue.

Cirrhinus mrigala (Hamilton, 1822) [2n = 50]: The diploid chromosome number of the C. mrigala was $2 n=50$. The chromosomes of $C$. mrigala did not show prominent C-bands (Fig. 3A). The Cheterochromatin was confined only to some of the chromosomes in the form of centromeric C- bands (Fig. 3B). Intercalary and telomeric C- bands were not observed on any chromosome. Ag- NOR staining (Fig.3C) elucidated the presence of darkly stained NORs on the terminal region of the long arms of one of the chromosome. Another homologue of this chromosome pair could not be localized due to scattering of chromosomes.

\section{DISCUSSION}

Cyprinid fishes are characterized by presence of 
Neeru et al. / J. Appl. \& Nat. Sci. 10 (2): 535 - 539 (2018)

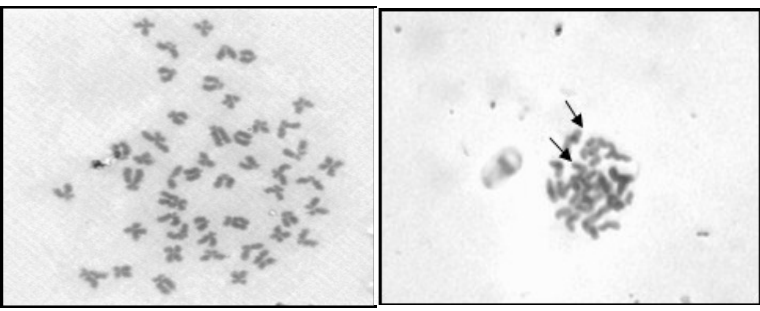

Fig. 1A. Somatic Fig. 1B. C- banded metaphase of C. catla. chromosomes of C. catla.

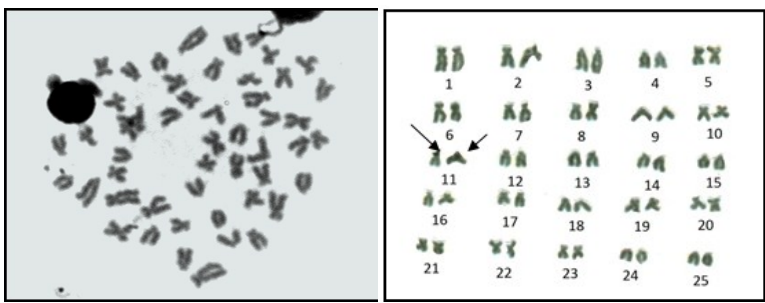

Fig. 1C. Silver stained Fig. 1D. Karyotype made somatic metaphase of $\mathrm{C}$. from silver stained somatcatla showing NORs.

ic metaphase of Catla catla showing NORs on $11^{\text {th }}$ pair

relatively small chromosomes with their centromeric positions ranging gradually from median to nearly terminal, making it difficult to assign some chromosomes to particular chromosomal categories and thus making correct identification of individual chromosomes nearly difficult/impossible (Rab and Collares-Pereira,1995; Suleyman et al., 2004) Moreover, identification of fish chromosomes is difficult due to the lack of any standard karyotype for fishes; polymorphism exists not only among various fish species but also within species (Al-Sabti, 1987) and also with varied ecological and geographical conditions. The karyological study of teleost fish present technical difficulties which are not encountered in the study of other vertebrates and these difficulties are due to small size and high number of chromosomes (Cucchi and Baruffaldi, 1990).

The most commonly occuring diploid number in family Cyprinidae is 50, considered to be the modal number in case of this family (Manna, 1984; Rishi, 1989). Karyotype studies of Indian major carps have been worked out by numerous scientists (Gui et al., 1986; Zhang et al., 1991; John et al., 1992; John et al., 1993, Jana, 1993; Nagpure et al., 2001) who reported similar results, i.e., $2 n=50$ which are in accordance with the present results and earlier publication of our laboratory (Bhatnagar et al., 2014)

Positive C-bands identify regions of constitutive heterochromatin, which contains transcriptionally inactive highly repetitive DNA sequences (Gold et al., 1990). Most species invariably possess Cbands at or around the centromeres (pericentromeric) and, frequently, at the chromosome end (telomeric). C-bands may also be found along the chromosome arms (interstitial) and as
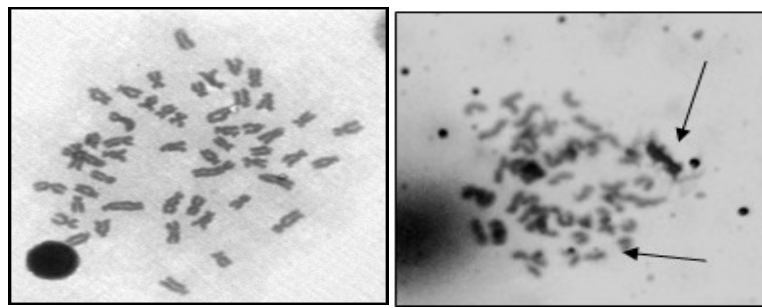

Fig. 2A. Somatic meta- Fig. 2B. C-banded chrophase of L. rohita. mosomes of L. rohita.

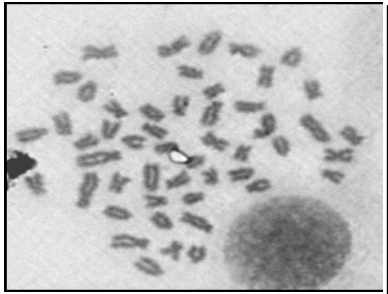

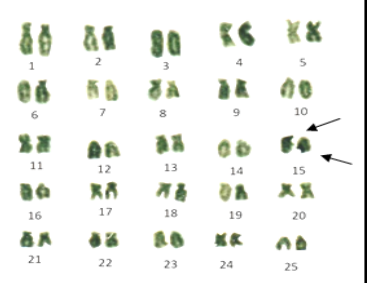

Fig. 2C. Silver stained Fig. 2D. Karyotype made somatic metaphase of from silver stained metaL. rohita showing NORs. phase showing NORs on $15^{\text {th }}$ pair.

entirely heterochromatic short arms of acrocentric chromosomes (Gold et al., 1986). Fishes with such characteristic C-band patterns mostly belong to Cyprinidae and other lower teleostean groups. Therefore, C-band distribution in Cyprinidae is of great cytotaxonomic interest (Takai and Ojima, 1988). Locations of NORs in the karyotype and NOR phenotypes have also been proven useful in cyprinid cytotaxonomy (Amemiya and Gold, 1988). Rishi and Mandhan (1995) observed centromeric, intercalary and telomeric $\mathrm{C}$ - bands in C. catla. The present study also showed similar results, in accordance with Rishi and Mandhan (1995) in C. catla. The first report on C-banding pattern in $L$. rohita appears to be that of Rishi and Mandhan (1990) followed by Khuda-Bukhsh and Chakrabarty (1994) and Nagpure (1997). The present results also support findings of Rishi and Mandhan (1990) regarding no intercalary Cbands, only centromeric and telomeric C- bands were obtained in L. rohita. On the other hand, the investigations of Nagpure (1997) on C-banding pattern of $L$. rohita revealed multisite distribution of C-band heterochromatin. Khuda-Bukhsh and Chakrabarty (1994) attempted to study the C-band pattern in Cirrhinus mrigala and L. rohita. It was reported that the majority of chromosomes showed C-banding localization in or around centromere, while some others either lacked or showed telomeric (terminal) or interstitial C-bands localization in both the species.

Chromosome banding studies are a step nearer to accuracy in enabling the identification of species and also homologous pairs in karyotypes. Similarly, banding of NORs also helps in this regard, as these are present on specific chromosomes (Nuclear chromosomes), it makes relatively easy 
Neeru et al. / J. Appl. \& Nat. Sci. 10 (2): 535 - 539 (2018)

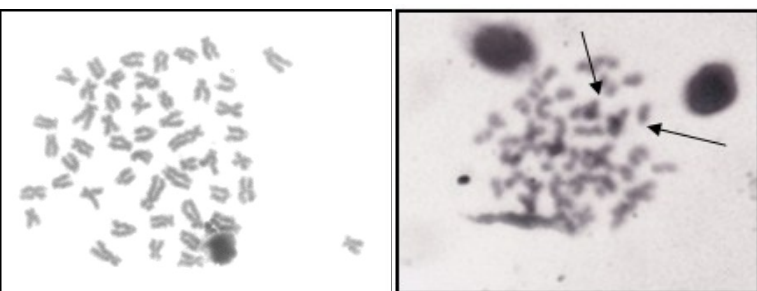

Fig. 3A. Somatic meta- Fig. 3B. C- banded phase of C. mrigala. chromosomes of $C$ mrigala.

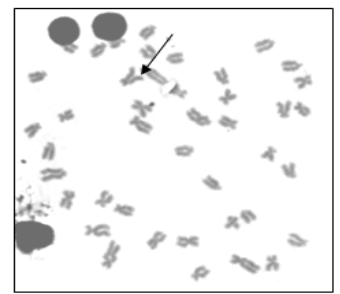

Fig. 3C. Silver stained chromosomes of C. mrigala.

to distinguish species with similar karyotypes (Sola et al., 1984). The study also may help in identifying the parentage of putative hybrids that are sometimes found in nature.

During the present investigations in C. catla, NORs were reported on only one pair of chromosome, i.e., $11^{\text {th }}$ chromosome pair which was submetacentric. John et al. (1992) observed NORs of minute size on two pairs of chromosomes (one submetacentric and one subtelocentric chromosome pairs), while Pal (1994) reported NORs on only on $7^{\text {th }}$ pair of chromosome, which was submetacentric. The present results are thus not in agreement with the observations of John et al. (1992) and showed similarity with the result of Pal (1994) in case of C. catla. Not very many studies are available on banding patterns in carps. John et al. (1992), Magtoon and Arai (1993) and Nandini and Arockia (2014) reported NORs on one pair of submetacentric chromosomes in L. rohita. Pal (1994) observed NORs on one pair of subtelocentric chromosomes in the same fish while Nagpure et al. (2001) reported NORs on two pairs of chromosomes. The present results also showed NORs only on one pair of subtelocentric chromosome $\left(15^{\text {th }}\right.$ chromosome pair) in $L$. rohita, and are in accordance with the observations of Pal (1994). Nagpure et al. (2001) reported NORs on only one pair of chromosome in C. mrigala. The NORs of species with the same diploid chromosome number were located in different chromosomes, despite their karyotypic similarity. These results suggest a close relation between the alteration of chromosomal locations of NORs and the species differentiation.

\section{Conclusion}

In conclusion, the chromosome number of three Indian major carp species C. catla (Hamilton, 1822), L. rohita (Hamilton, 1822), C. mrigala
(Hamilton,1822) revealed the same diploid number $(2 n=50)$. The variation in banding pattern of chromosomes was observed with respect to species suggesting that diversification in these fishes of the same family is related to structural changes in chromosomes. The differences in banding pattern were also observed in comparison to earlier studies, may be due to various human activities affecting the ecology of water bodies. The present study clearly suggests that there is a need to obtain data on cytogenetic variations of different fish species with respect to time and also changes in aquatic ecological conditions and a databank should be prepared.

\section{ACKNOWLEDGEMENTS}

The authors are thankful to the Chairperson, Department of Zoology, Kurukshetra University, Kurukshetra, India, for providing laboratory and library facilities and to UGC (F.3-9/DRS-I, SAP-II) for support.

\section{REFERENCES}

Abdoli, A. (1999). The Inland water fishes of Iran. Natural and wildlife museum of Iran, Tehran. 378.

Al-Sabti, K. (1987). Cytogenetic studies on five species of Pisces from Yugoslavia. Cytobios. 49(198-199): 175-188.

Amemiya, C.T. and Gold, J.R. (1988). Chromosomal NORs as taxonomic and systematic characters in North American cyprinid fishes. Genetica. 76: 81-90.

Bhatnagar, A. Yadav, A.S. and Kamboj, N. (2014). Karyomorphology of three Indian major carps from Haryana, India. J. FisheriesSciences.com. 8(2): 95-103.

Cucchi, C. and Baruffaldi, A. (1990). A new method for karyological studies in teleost fishes. J. Fish Biol. 37: 71-75.

Gold, J.R. Amemiya, C.T. and Ellison, J.R. (1986). Chromosomal heterochromatin differentiation in North American cyprinid fishes. Cytologia. 51: 557566.

Gold, J.R. Li, Y.C. Shipley, N.S and Powers, P.K. (1990). Improved methods for working with fish chromosomes with a review of metaphase chromosome banding. J. Fish Biol. 37: 563-575.

Gui, J.Y. Li, K. and Zhou, T. (1986). Transactions of the Chinese Society of Ichthyology. Science Press Beijing. 7: 115-123.

Howell, W.M. and Black, D.A. (1980). Controlled silverstaining of nucleolus organizer regions with a protective colloidal developer: A 1-step method. Experentia. 36(1): 1014-1015.

Jana, R.K. (1993). Studies on some aspects of biology and cytogenetics of rohu-catla and catla-rohu hybrids. Thesis submitted for the degree of Doctor of philosophy (Science) of the University of Calcutta.

Jayaram KC. (1999). The Freshwater fishes of the Indian region. Narendra Publishing House, Delhi.

Johal, M.S. and Jha, S.K. (2010). Ichthyofaunal composition and conservation status of five North Indian States (Haryana, Himachal Pradesh, Punjab, Rajasthan and Uttrakhand). Res.Bull.Pun.Uni. 60: 19-39.

John, G. Barat, A and Lakra, W.S. (1992). Localization of nuclear organizer regions in fish species, Catla 
catla and Mystus vittatus. The Nucleus. 35(2-3):179181

John, G. Barat, A and Lakra, W.S. (1993). Localization of nuclear organizer regions in Labeo rohita (Cyprinidae). La Kromosoma. 70: 2381-2384.

Kalbassi, M.R. Hosseini, S.V and Tahergorabi, R. (2008). Karyotype Analysis in Schizothorax zarudnyi from Hamoon Lake, Iran. Turk. J. Fish. Aqua Sci. 8: 335-340.

Khan, T.A. Bhise, M.P. and Lakra , W.S. (2000). Chromosome manipulation in fish: a review. Ind J Ani Sci. 70(3): 213-221.

Khuda-Bukhsh, A.R and Chakrabarty, C. (1994). Localization of C-band heterochromatin in metaphase chromosomes of two species in Indian major carps. Inland Fish. Soc. Ind. 26: 44-46.

Lakra, W.S. Nagpure, N.S. Kumar, R. Kushwaha, B. Singh, P.J. and Srivastava, S.K. (2007). Genotoxic Assessment in fishes -A Practical manual NBFGR Publications. 1-71.

Magtoon, W. and Arai, R. (1993). Karyotype and distribution of nucleolus organizer regions in cyprinid fishes from Thailand. Japan. J. Ichthy. 40(4): 77-86.

Manna, G.K. (1984). Progress in fish cytogenetics. The Nucleus. 27: 203-231.

Nagpure, N.S. (1997). Distribution of C- band heterochromatin in Labeo rohita (Ham.) (Cyprinidae). Chrom. Sci. 1: 45-46.

Nagpure, N.S. Srivastava, S.K. Kushwaha, B. and Ponniah, A.G. (2001). Current status on Cytogenetics of North East Indian Fishes. P.161-167. In A.G. Ponniah and U.K. Sarkar (eds.). Fish Biodiversity of North East Indian Fishes NBFGR-NATP PUBL. 2: 228.

Nandini, S. and Arockia Rita J.J. (2014). Karyomorphology of two major carps, Catla catla and Labeo rohita. Biores. Bull.1:1-7

Neeru. (2014). A study of Fish Biodiversity and Karyology of Commercially Important Fish Species of Haryana. Thesis submitted for the degree of Doctor of philosophy (Science) to the Kurukshetra University.

O'Connor, C. (2008). Karyotyping for chromosomal abnormalities. Nat. Edu. 1: 27.

Pal, R. (1994). Cytogenetic analysis in some fishes belonging to family cyprinidae. Ph.D. Thesis. Kurukshetra University, Kurukshetra.
Rab, P. and Collares-Pereira, M.J. (1995). Chromosomes of European cyprinid fishes (Cyprinidae, Cypriniformes): a review. Folia Zoologica. 44: 193-214.

Rishi, K.K. (1989). Current status of fish cytogenetics. In: Fish Genetics in India. (eds Das, P. and Jhingran, V. G.) Today and tomorrows Printers and publishers, New Delhi.; 728-756.

Rishi, K.K and Mandhan, R.P. (1990). Analysis of Cbanded heterochromatin in the chromosomes of $\mathrm{Lab}$ eo rohita (Ham.) (Cyprinidae). Chrom. Inf. Ser., 48:3-4

Rishi, K.K and Mandhan, R.P. (1995). Study of Cbanding, G- banding and Ag-NORs in the chromosomes of the Indian major carp, Catla catla (Family Cyprinidae, Pisces). Persp. Cyto. Gen. 8: 371-375.

Sola, L. Camerini, B. and Cataudella, S. (1984). Cytogenetics of Atlantic eel, C-and G-banding, nucleolus organizer regions and DNA content. Cytogenetics. 38: 206-210.

Suleyman, G. Ahmet, C. Ilhan, S. and Bertal, K. (2004). Karyotype analysis in Alburnus heckeli (Battalgil, 1943) from lake Hazer. Turk. J. Vet. Ani. Sci. 28: 309314.

Sumner, A.T. (1972). A simple technique for demonstrate centromeric heterochromatin. Exper. Cell Res. 75: 304-306.

Takai, A. and Ojima, Y. (1988). Chromosomal Distribution of Nucleolus Organizer Regions in Six Species of Rhodeinae (Cyprinidae, Pisces). Proceed. Japan Acad. Sci. 64(3): 49-52.

Tan, X. Jian, G.Q. Chen, B. Chen, L and Li, X. (2004). Karyological analyses of redclaw crayfish Cherax quadricarinatus (Decapoda: Parastacidae). Aquaculture. 234: 65-76.

Tjio, J.H and Whang, J. (1965). In: Human chromosome methodology. Newyork, Academic press.

Unal,S. Gaffaroglu, M. Ayata, K.M. and Yuksel,E.2014. Karyotype, C-banding and Ag-NORs of two endemic leuciscine fish, Pseudophoxinus crassus and $P$. hittitorum (Teleostei, Cyprinidae). Comp Cytogen. 8: 249-257.

Zhang, S.M. Reddy, P.V.G.K and Khan, H.A. (1991). Karyomorphological studies in four species of freshwater fishes from India. Veterinary Archives. 61:5763 